\section{Commentary: Biventricular conversion after Fontan completion - what have we learned so far?}

\author{
Paul J. Chai, MD
}

There are many questions in congenital heart surgery that remain unanswered. Whether a biventricular repair is necessarily better than a univentricular repair is one question that is particularly difficult to know. The true benefits of a biventricular repair may only be realized after many years, and no realistic control group exists for a definitive trial to examine this topic. In this issue of the Journal, Doulamis and colleagues ${ }^{1}$ attempt to tackle this question and present their preliminary Boston experience with biventricular conversion after Fontan completion. A total of 23 patients from 2007 to 2020 underwent Fontan takedown and conversion to a biventricular physiology. Patient selection was based on a multitude of factors. Fifteen of these patients had "failing Fontan" physiology, and 8 were elective. Six patients underwent procedures for staged recruitment of the nondominant ventricle before conversion. Median followup was only 1.1 years. There were 5 deaths ( $22 \%$ mortality) in this cohort. Given that the mortality rate for a patient with a failing Fontan could be high, the authors concluded that biventricular conversion is a feasible option with acceptable survival, although it certainly requires further evaluation.

In this Boston study, freedom from reoperation/reintervention was only $20 \%$ at 5 years, indicating a significant ongoing requirement for reintervention. In total, 13\% required reoperation, including multiple valve replacements and a Ross procedure. Almost one half required recatheterization for reintervention on outflow tracts, pulmonary arteries, valves and septal defects, and coronary arteries. In total, $36 \%$ of

\footnotetext{
From the Division of Cardiothoracic Surgery, Department of Surgery, Children's Healthcare of Atlanta; and Emory University, Atlanta, Ga.

Disclosures: The author reported no conflicts of interest.

The Journal policy requires editors and reviewers to disclose conflicts of interest and to decline handling or reviewing manuscripts for which they may have a conflict of interest. The editors and reviewers of this article have no conflicts of interest.

Received for publication May 6, 2021; revisions received May 6, 2021; accepted for publication May 7, 2021; available ahead of print May 12, 2021.

Address for reprints: Paul J. Chai, MD, Division of Cardiothoracic Surgery, Department of Surgery, Children's Healthcare of Atlanta, 1405 Clifton Rd NE, Atlanta, GA 30322 (E-mail: paul.chai@ choa.org).

J Thorac Cardiovasc Surg 2022;163:1224-5

$0022-5223 / \$ 36.00$

Copyright $($ c 2021 by The American Association for Thoracic Surgery

https://doi.org/10.1016/j.jtcvs.2021.05.014
}

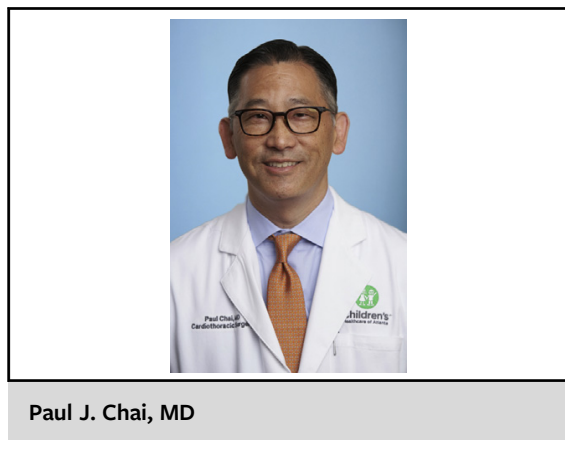

CENTRAL MESSAGE

The benefits of biventricular conversion after Fontan completion remain unclear. True benefits won't be clear for many years.

patients had right ventricular (RV) systolic dysfunction with $\mathrm{RV}$ pressures greater than two-thirds systemic pressure, and the median left ventricular end-diastolic pressure in the cohort was $15 \mathrm{~mm} \mathrm{Hg}$. Left ventricular diastolic dysfunction and compliance issues resulting in elevated RV pressures rarely improve and can be very difficult to manage medically.

It's difficult to determine whether conversion to biventricular physiology constitutes a better state. True benefit would only be realized after an extended period, and this would have to be considered in the context of likely introduced increased rates of reintervention (conduit changes, for example) or morbidity (pacemaker insertion in 4 patients). One could argue that like the "failing Fontan," long-term failure of patients with biventricular circulation but complex reconstruction (conduits, valve repair/replacement) is also inevitable, as life expectancy in these patients is also reduced compared with the rest of the population. How much intervention is too much for a patient? Should the level of surgical intervention required to achieve a biventricular conversion play a role in determining suitability? Are we making these patients less-suitable transplant candidates because of continued exposure to elevated end-diastolic pressures or increased exposure to homograft usage for conduit placements? These are important questions to consider.

The authors present a thoughtful discussion and acknowledge the heavy toll that reinterventions and reoperations could take. The sense that patients with a Fontan circulation are destined for failure may not always be an accurate one but is certainly a thought that many consider for 
the long term. Even transplantation is not a durable solution, and so exploring alternative solutions for these patients is a necessary and desirable endeavor.

\section{Reference}

1. Doulamis IP, Marathe SP, Piekarski B, Beroukhim RS, Marx GR, del Nido PJ, et al. Biventricular conversion after Fontan completion: a preliminary experience. J Thorac Cardiovasc Surg. 2022;163:1211-23.
See Article page 1211.

\section{Commentary: Time for a new maxim}

David S. Winlaw, MD, MBBS,

Alexander R. Opotowsky, MD, MMSc, and

James S. Tweddell, MD

In this study, ${ }^{1}$ we are reminded that initial decision making regarding 1- versus 2-ventricle pathways for complex anatomical substrates is a subjective process and is subject to institutional, experiential, and societal influences. The consequences of this decision may not be evident for decades.

Twenty years ago, we heard the maxim that $a$ good Fontan is better than a bad 2-ventricle circulation. This was often said in contemplation of an operation that required creation of a complex pathway from left ventricle to aorta. The emerging narrative about long-term Rastelli procedure outcomes seemed to support this notion. ${ }^{2}$ We and others reported better-than-expected outcomes of the Fontan circulation ${ }^{3,4}$ and in the drive to reduce operative mortality, a subset of 2ventricle candidates presumably underwent Fontan procedures. With the suite of investigations currently employed to assess ventricle size, systolic and diastolic function, better imaging, and perioperative care as well as accumulated data and wisdom, such patients may now be more appropriately and objectively streamed. Nevertheless, there remains a sizeable, subjectively defined gray area. In this experience, it was notable that 8 asymptomatic patients who underwent elective

\footnotetext{
From the Department of Cardiothoracic Surgery, Heart Institute, Cincinnati Children's Hospital, Cincinnati, Ohio.

Disclosures: The authors reported no conflicts of interest.

The Journal policy requires editors and reviewers to disclose conflicts of interest and to decline handling or reviewing manuscripts for which they may have a conflict of interest. The editors and reviewers of this article have no conflicts of interest.

Received for publication May 11, 2021; revisions received May 11, 2021; accepted for publication May 12, 2021; available ahead of print May 20, 2021.

Address for reprints: David S. Winlaw, MD, MBBS, Department of Cardiothoracic Surgery, Heart Institute, Cincinnati Children's Hospital Medical Center, MLC 2013,3333 Burnet St, Cincinnati, OH 45229-3026 (E-mail: david.winlaw@ cchmc.org).

J Thorac Cardiovasc Surg 2022;163:1225-6

$0022-5223 / \$ 36.00$

Copyright (C) 2021 by The American Association for Thoracic Surgery

https://doi.org/10.1016/j.jtcvs.2021.05.025
}

Check for updates

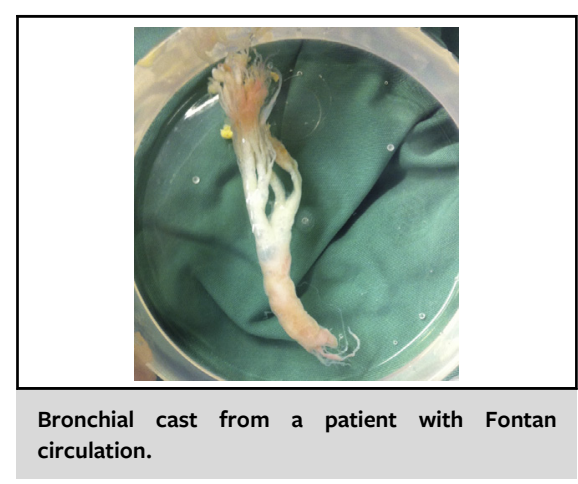

CENTRAL MESSAGE

When 1-step conversion from

Fontan to biventricular physi-

ology is done early and electively,

good outcomes can be achieved.

In those who require staged pro-

cedures, the benefit is less clear.

and primary conversion to 2 ventricles all survived and may, in retrospect, have been good 2-ventricle candidates.

More recently, Fontan pessimism has waxed, with the maxim changing to: There is no such thing as a good Fontan. No doubt this view is gaining ground because of the burgeoning population of adults with a deteriorating Fontan circulation, including impaired exercise capacity, arrhythmia, heart failure, and multisystem dysfunction (eg, liver, kidney, pulmonary, lymphatic, and others). ${ }^{5}$ A Fontan circulation with 2 ventricles does not fare better than single-ventricle Fontans, ${ }^{6}$ highlighting the deficiencies of the Fontan circulation itself. Such is the belief in this maxim that the conclusion of this article ${ }^{1}$ is that elective takedown to 2 ventricles should be considered in "well-functioning" Fontan patients. The caveat? Whether or not one intervenes, functioning well in the present is an excellent predictor of functioning well in the future. Absence of a contemporaneous comparison group of well Fontan patients who did not undergo biventricular repair and Fontan transplant recipients remains a 